\title{
Research and application of electricity price compensation analysis model
}

\author{
Dongxue $\mathrm{Li}^{1, \mathrm{a}}$, Dayong $\mathrm{Yu}^{1, \mathrm{~b}}$, Ran $\mathrm{Liu}^{1, \mathrm{c}}$ \\ ${ }^{1}$ State Grid Liaoning Electric Power CO,LTD. Power Electric Research Institute, Shenyang ,110015, \\ China \\ a email: Idxztg79@163.com, bemail: ydy_jyy@In.sgcc.com.cn, cemail: Ir_jyy@In.sgcc.com.cn
}

Keywords: Wind power on power grid; Grid sale price; Analytical model; Peak shaving; Absorption

\begin{abstract}
In recent years, the national renewable energy industry policies and incentives, Liaoning wind power has developed rapidly. However, the Liaoning Province endogenous wind power grid connected capacity increases year by year, squeezing annual utilization rate of the thermal power unit in the province. And the thermal power units based on the number of hours declined year by year, peak shaving capacity issues within the grid, peaking difficulties. In addition, the basic peak shaving or depth peak shaving for the thermal power units will increase the coal consumption rate and the generation price. The reason is that the price caused by the coal consumption increasing is not compensated. This paper considers wind power generation corporations' and thermal power generation corporations' benefits and sets up wind and thermal compensation price analysis model. The wind and thermal compensation scheme is set reasonably to mobilize the enthusiasm of the thermal power grid peak shaving and ensure the full utilization of wind power resources, enhance the comprehensive benefits of power generation corporations.
\end{abstract}

\section{Introduction}

"The guidance for improving the power operation and regulation to promote clean energy more power generation and full power generation” released by National Energy Bureau suggested that the power generation corporation should set up the compensation cost according to its own operation $[1,2]$, and the cost should be corresponding shared by the benefit of renewable energy and the thermal power unit according to the degree $[3,4]$.

In order to encourage thermal corporations to actively participate in the power grid shaving, power grid structure optimization and resource allocation optimization [5,6], this paper considers wind power generation corporations' and thermal power generation corporations' benefits and sets up wind and thermal compensation price analysis model [7]. By reasonably setting the wind and thermal compensation scheme to mobilize the enthusiasm of the thermal power grid shaving and ensure the full utilization of wind power resources, enhance the comprehensive benefits of power generation corporations $[8,9]$.

\section{Power generation statuses in Liaoning province}

\section{Installed power capacity}

According to the statistics, the power supply of Liaoning province is dominated by thermal power (more than 30000MW), and the wind power is second, and the other power supply is relatively small. By the end of 2014, in Liaoning Province, the installed power generation capacity of 41918.3MW, of which installed thermal power capacity and wind power capacity of $30837.800 \mathrm{MW}$ and $6083.9 \mathrm{MW}$, accounting for $73.57 \%$ and $14.51 \%$ of the total proportion of the province's total correspondingly. All kinds of power equipment capacity accounted for as shown in figure 1.

The regional installed wind power capacity planning, wind power is installed mainly in Fuxin, Tieling, Dalian, Chaoyang and Shenyang. 


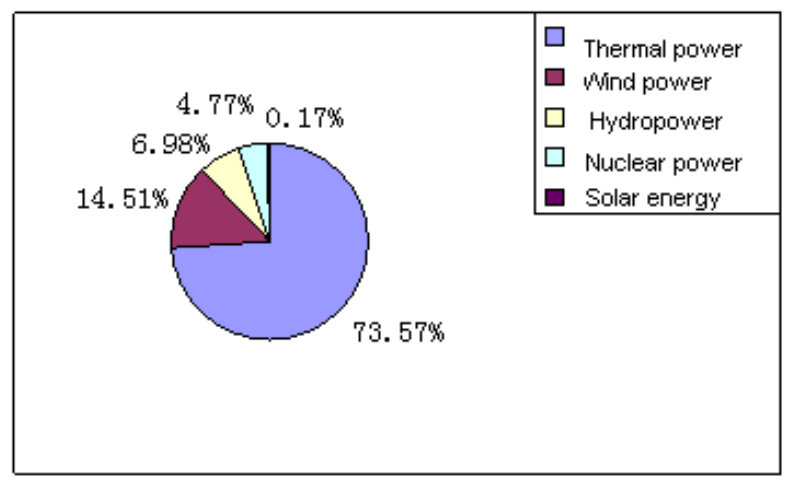

Fig.1. Liaoning power grid power structure in 2014From 2020 to 2010 in Liaoning

\section{Wind power utilization hours}

The wind power generating unit utilization hours (month, year) equals to the wind power generating capacity (month, year) divided by the rated installed power generation capacity. And it reflects the equipment utilization rate of wind farm. According to the statistics in 2013, the maximum value of wind power generating units (monthly) appears in November, and the minimum value appears in February. And the annual utilization hour of wind power units are 1695.8 hours.

The utilization hour of wind power units in our country is lower than 2000 hours, while foreign countries are more than 2000 hours. In this aspect, Liaoning power grid can take appropriate measures to improve utilization hour of the wind power generation unit having been put into operation for rational using of existing resources in the expansion of the installed power generation capacity of the wind power unit.

\section{Wind and thermal compensation price analysis model}

Assuming that wind power grid access certain capacity, required by the thermal generating units with the depth of power grid peak shaving. The establishment of the model needs to set the following basic parameters:

(I).Basic parameters setting of thermal power units: Single power unit' s capacity Pfmax, the number of units $\mathrm{N}$, unit minimum outputPfmin, thermal power plant coal consumption rate parameters(Consumption characteristic coefficient ai, bi and ci), pollutant discharge rate of thermal power units, pollutant environmental value of thermal power units.

(II).Power market parameter setting: wind power price Pricew, thermal power price Pricef, thermal power compensation price Pricefb, Electricity market price and Carbon emissions market price.

(III).Calculated initial values: access capacity of thermal power units Pf, and its decreasing step size Pfde, access capacity of wind power units Pw, and its increasing step size Pwadd, wind power price Pricew and its decreasing step size Pricewde, thermal compensation price Pricefb and its increasing step size Pricefbadd.

The calculation process is shown in figure 2.

When the thermal power unit output change, additional power grid peak shaving cost caused by coal consumption increased. Thermal power generation coal consumption is a function of the unit output, decreased with increasing output power of wind turbine, such as formula (1). The general power consumption can be expressed as two function form:

$$
\mathrm{b}_{\mathrm{g}-\mathrm{i}}(\mathrm{t})=\mathrm{f}_{1}\left[\mathrm{P}_{\mathrm{Gi}}(\mathrm{t})\right]=\mathrm{A}_{\mathrm{i}} \quad \mathrm{P}_{\mathrm{Gi}}(\mathrm{t})^{2}+\mathrm{B}_{\mathrm{i}} \quad \mathrm{P}_{\mathrm{Gi}}(\mathrm{t})+\mathrm{C}_{\mathrm{i}}
$$

Among them: $A_{\mathrm{i}} 、 B_{\mathrm{i}}$ and $C_{\mathrm{i}}$ are the coefficient of consumption characteristics of the fitting. $\mathrm{b}_{\mathrm{g}-\mathrm{i}}(\mathrm{t})$ and $P_{\mathrm{Gi}}(\mathrm{t})$ are power consumption rate of thermal power unit $\mathrm{i}$ and its output power respectively. Unit name is $\mathrm{g} / \mathrm{kWh}$ and $\mathrm{MW}$. The wind before and after the change, the coal consumption of thermal power units $\triangle \mathrm{b}_{\text {g-i }}(\mathrm{t})$

$$
\triangle \quad b_{g-i}(t)=f_{1}\left[P_{f}\right]-f_{1}\left[P_{f}+P_{w}\right]
$$

According to the basic parameters of the coal price Pricecoal thermal power peaking cost Costf 
(unit name: yuan/kWh):

$$
\operatorname{Cost}_{\mathrm{f}}=\triangle \mathrm{b}_{\mathrm{g}-\mathrm{i}}(\mathrm{t}) \times \text { Price }_{\text {coal }} \times 10^{6}
$$

According to the incremental step size in the basic parameters, the power compensation price is automatically increased, and the wind power price is decreased, which can be accounted for the reasonable power compensation price.

$$
\begin{gathered}
\text { Price }_{\mathrm{fb}}=\text { Price }_{\mathrm{fb}}+\triangle \text { Price }_{\mathrm{fb}} \\
\text { Price }_{\mathrm{w}}=\text { Price }_{\mathrm{w}}-\triangle \text { Price }_{\mathrm{w}}
\end{gathered}
$$

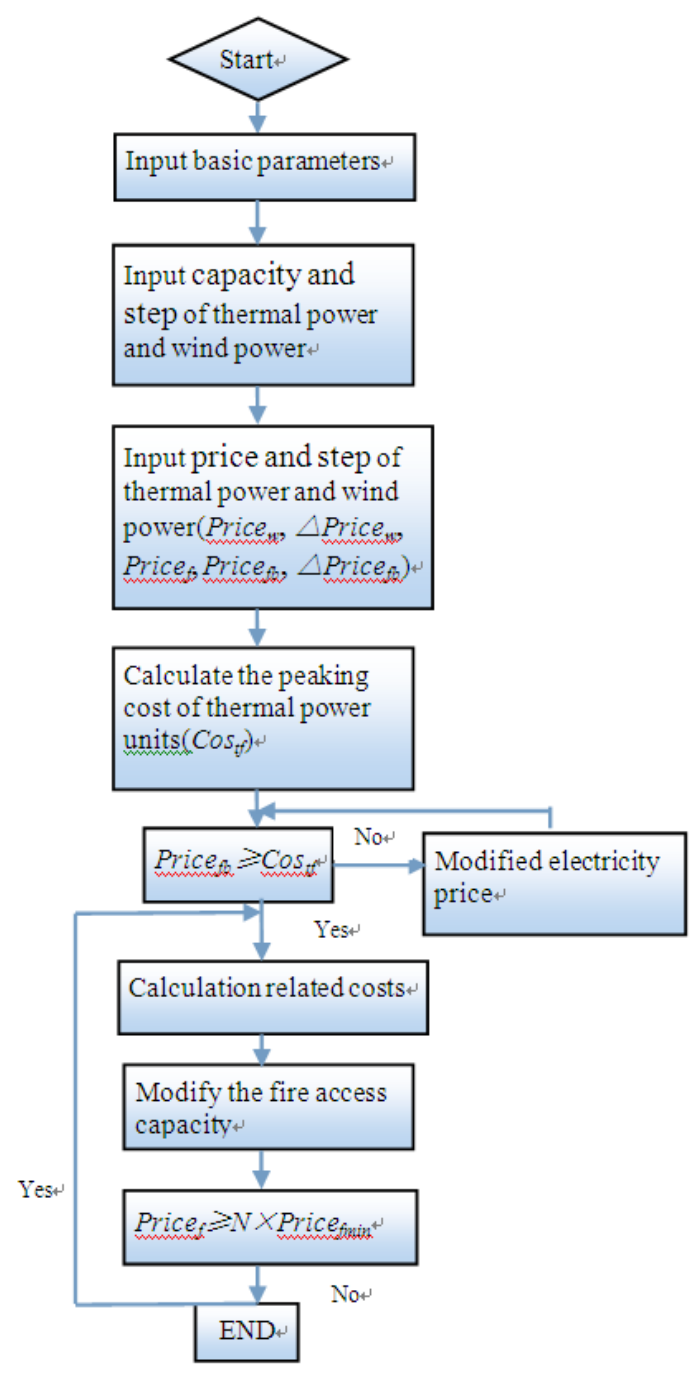

Fig.2. Analysis and calculation of hot flow compensation price

\section{Case study}

The transmission capacity of a regional power grid is $900 \mathrm{MW}$, the installed power capacity of regional thermal power unit is $3 * 300 \mathrm{MW}$, the total is $900 \mathrm{MW}$, the thermal power price is 0.36 yuan $/ \mathrm{kWh}$. Contribute to the $50 \%$ considering of the maximum depth of the peak thermal power units, the maximum access capacity of wind power is $45 \mathrm{MW}$, wind power electricity price 0.56 yuan $/ \mathrm{kWh}$. In the grid connected wind power impact on power system operation and economic benefit analysis model based on the theory, accounting for wind power generator connected to the grid electricity cost, thermal power plant coal consumption increased costs, benefits of saving coal, wind power

Environmental benefits, carbon emission rights value etc. of the project and get comprehensive benefits change rate of wind power integration capacity change of the graph. As shown in figure 3. The pollutant discharge rate of thermal power units, the environmental value of pollutants in thermal power units are shown in table 1 and table 2. 
Tab.1. Standard for environmental value of pollutants in thermal power (RMB/kg)

\begin{tabular}{|c|c|c|c|c|c|c|}
\hline Classifi-cation & $\mathrm{SO}_{2}$ & $\mathrm{NO}_{\mathrm{x}}$ & $\mathrm{CO}$ & $\mathrm{CO}_{2}$ & TSP & Waste water \\
\hline EVS & 6 & 6 & 1 & 0.023 & 2.2 & 0.0008 \\
\hline
\end{tabular}

Tab.2. Reference value of pollutant emission rate for fossil fired power plant (kg/tsc)

\begin{tabular}{|c|c|c|c|c|c|}
\hline Classifi-cation & SO2 & NOX & CO & CO2 & TSP \\
\hline ER & 0.8 & 0.35 & 0.23 & 2490 & 0.45 \\
\hline
\end{tabular}

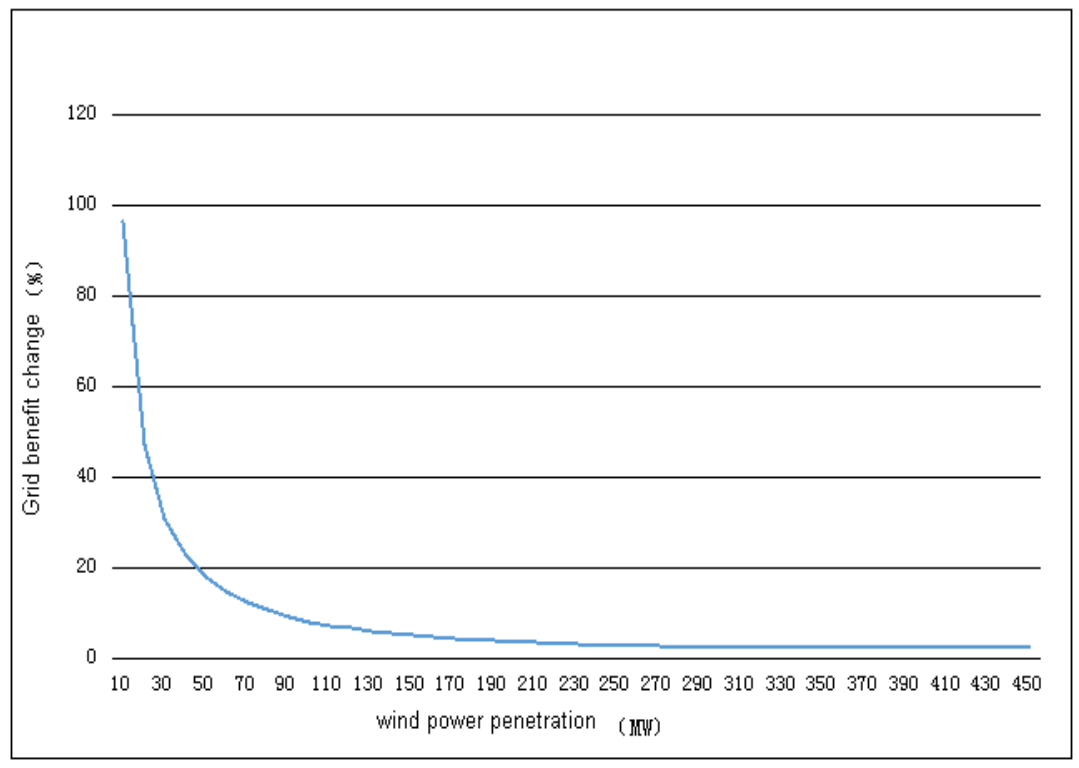

Fig.3. The comprehensive benefit change rate curve of power grid.

When the power grid wind power access capacity exceeds $80 \mathrm{MW}$, the power grid comprehensive efficiency change is less than $10 \%$, that is to continue to increase the wind power capacity of the grid to bring the overall benefits of the power grid is not more than 0.1 times the original comprehensive benefits. At the same time, thermal power units because output is reduced, resulting in increased rate of coal consumption of thermal power units, to increase the cost of coal consumption, as shown in figure 4.

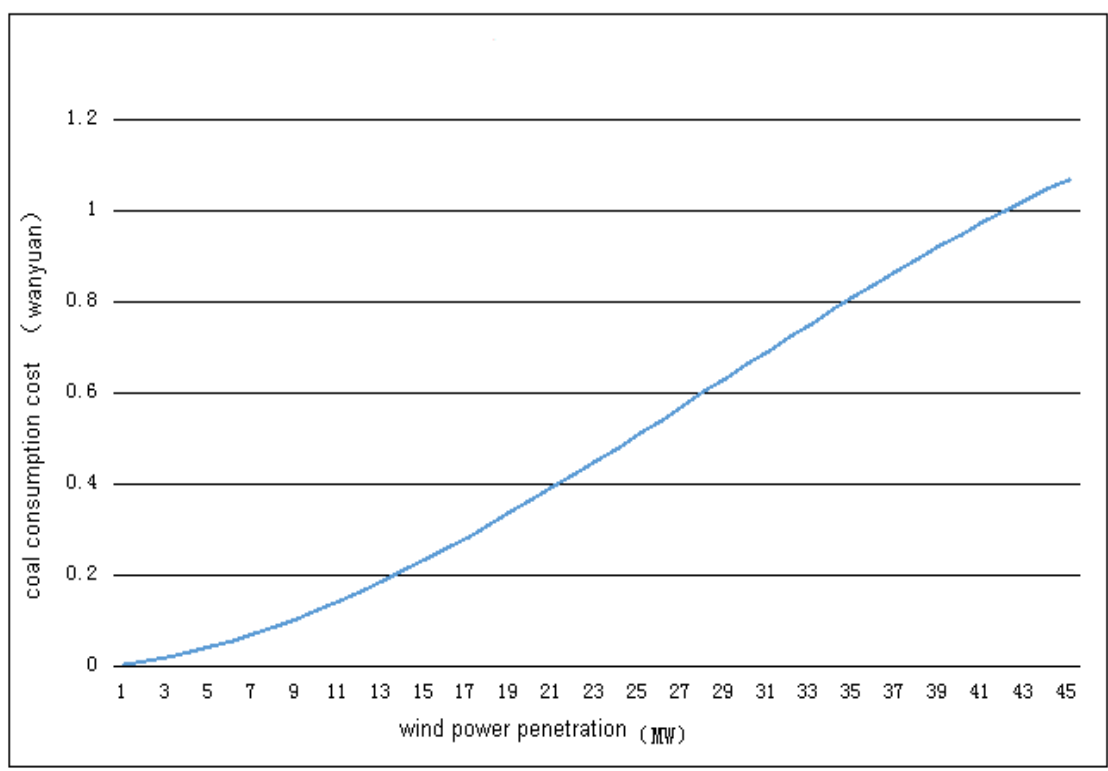

Fig.4. Thermal power grid peak shaving coal cost curve.

By wind and thermal compensation analysis model, the compensation scheme is obtained under different wind power access capacity as shown in table 3. 
Tab.3. Analysis results of wind and thermal power compensation scheme

\begin{tabular}{|c|c|c|c|}
\hline & Wind power access capacity (MW) & $\begin{array}{c}\text { Wind power price } \\
\text { (yuan/kWh) }\end{array}$ & $\begin{array}{c}\text { Thermal power price } \\
\text { (yuan/kWh) }\end{array}$ \\
\hline 1 & $<70$ & 0.55 & 0.37 \\
\hline 2 & $<240$ & 0.54 & 0.38 \\
\hline 3 & $<450$ & 0.53 & 0.39 \\
\hline
\end{tabular}

The results show that the maximum of the thermal power plant can be coordinated with the 450MW wind power capacity.

When the thermal power plant coordinated accesses 0 70MW wind power capacity, the price should be set to 0.01 yuan / $\mathrm{kWh}$ thermal power compensation. When the thermal power plant coordinated accesses 70 240MW wind power capacity, the price should be set to 0.02 yuan / kWh thermal power compensation. When the thermal power plant coordinated accesses $240 \sim 450 \mathrm{MW}$ wind power capacity, the price should be set to 0.03 yuan / kWh thermal power compensation.

\section{Conclusion}

According to the Liaoning power grid by extrusion thermal power units to improve the wind power utilization situation, in view of existing situation that decreasing generating capacity of the thermal power unit and increasing generating capacity of the wind power unit in Liaoning power grid, this paper presents wind and thermal power price compensation model and gets the power price and gives different wind power capacity of wind power enterprise compensation price standard of thermal power enterprises. Technical support for the implementation of the relevant compensation policies is provided. The wind and thermal compensation scheme is set reasonably, to further mobilize thermal power peaking enthusiasm, and improve the utilization of clean energy wind power.

\section{References}

[1] Huang Suyi. Beijing: China Electric Power Press, 2004

[2] Zhao Haixiang. Voltage fluctuation and flicker caused by wind power research [D]. China Electric Power Research Institute, 2005

[3] Li Qionglin, Tian Chunzheng, Song Xiaokai. Modeling of wind farm and its analysis on the stability of access network [J]. power system protection and control, 2009,37 (19): 46-51.

[4] Chi Yongning, Liu Yanhua, Wang Weisheng et al. Effect of wind power on power system [J]. power system technology, 2007,31 (3): 77-81.

[5] Li Shanying, Shi Qingxin. Research on the power of large scale wind farm connected to grid connected operation [J]. 2010,43 (China), (9): 71-74.

[6] Li Yiyan, tie Jiang Yuan, Chao Qin. Reactive power compensation strategy [J]. Low voltage apparatus based on PSCAD wind power grid connected power systems, 2009 (19): 12-15.

[7] Yu Haimiao,Zhou Haizhu, Pei Xiaomei. Environmental value and economic analysis of wind power [J]. Journal of Tongji University, 2009,37 (5): 704-707.

[8] Zhang Lefeng, Wang Zengping. Influence of wind power grid connected power system [J]. Jiangsu electric engineering, 2011,30 (2): 81-84.

[9] Lei Yazhou. Research on the subject of wind power grid connected [D], power system automation.2003,27 (8): 84-89. 